\title{
Lev Vigotski, a Revolução de Outubro e a questão judaica: o nascimento da teoria histórico-cultural no contexto revolucionário
}

\author{
Zoia Prestes, ${ }^{I, \star}$ Elizabeth Tunes ${ }^{I I}$ \\ ${ }^{I}$ Universidade Federal Fluminense, Niterói, RJ, Brasil

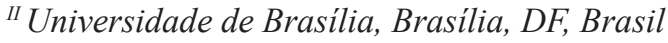

\begin{abstract}
A verdadeira história de Vigotski não precisa de lendas, pois é suficientemente interessante para abrir mão delas.

Guillermo Blanck
\end{abstract}

Duas questões a respeito da vida de L. S. Vigotski estudioso soviético que, nos dias de hoje, dispensa apresentação - são aqui examinadas. Uma diz respeito ao seu compromisso e participação no processo revolucionário que culminaria com a Revolução de Outubro de 1917 e a outra, ao seu envolvimento com a questão judaica.

Há cem anos, a Revolução Socialista liderada por Lenin aniquilou o regime secular tzarista na Rússia. As primeiras tarefas apresentadas pelo novo poder soviético instalado, depois de outubro de 1917, estavam intimamente relacionadas às demandas urgentes da nova sociedade a ser erigida, baseada nos princípios da igualdade, da liberdade e da fraternidade. Além disso, defendia-se a terra para os camponeses, o pão para os famintos e a paz para o povo.

Dentre as inúmeras tarefas, estava na ordem do dia a criação de uma nova escola que precisaria, por sua vez, de uma nova pedagogia. Tendo em vista a plurinacionalidade existente na Rússia, que se ampliou com a adesão de outros países (Ucrânia, Bielorrússia, entre outros) ao processo revolucionário, o objetivo era pensar uma escola pública, popular, gratuita e laica. Muitos psicólogos receberam com entusiasmo a Revolução e aderiram ao trabalho que se apresentava - estruturação do sistema de educação - e se dedicaram a buscas de novas formas e novos métodos para o trabalho pedagógico. Na União Soviética, a psicologia começava a fazer parte do rol de campos de conhecimento que fundamentavam a pedagogia. A psicologia soviética esteve, assim, desde o início de sua trajetória, internamente ligada às novas condições econômico-sociais e político-ideológicas da União Soviética (DAVIDOV, 1982).

A tarefa que se apresentava não era fácil, pois, para criar uma nova escola, seria preciso pensar numa nova pedagogia e uma nova psicologia fundamentadas nas ideias do materialismo histórico-dialético. Além disso, era necessário um olhar crítico para as teorias burguesas hegemônicas e uma forte resistência às suas influências, já que a psicologia soviética destacava a escola, a formação e a educação do novo homem como objetivos principais de suas pesquisas. A atuação de P. P. Blonski, M. Ia. Bassov, L. V. Zankov, A. R. Luria, A. N. Leontiev e L. S. Vigotski destacava-se no cenário científico sovié-

\footnotetext{
^Universidade Federal Fluminense, Faculdade de Educação. Rua Prof. Marcos Waldemar de Freitas Reis, Campus do Gragoatá, Bloco D - São Domingos, Niterói, RJ - Brasil. CEP: 24210-201.E-mail: zoiaprestes@yahoo.com.br, bethnunes@gmail.com
}

tico daquela época, pois suas investigações empreendiam esforços para indicar caminhos para as questões urgentes da educação de crianças e adolescentes e tinham como eixo norteador a formação do homem novo.

É importante lembrar que, ao final de 1917, o jovem Lev Vigotski estava se formando, concomitantemente, em duas Universidades e em dois cursos diferentes. $\mathrm{Na}$ Universidade de Moscou, recebeu o diploma de advogado e, na Universidade Popular Chaniavski, se formou em História e Filosofia.

O que se sabe, de fato, a respeito de como o jovem profissional que se formava vivenciou o processo revolucionário na Rússia e em seu país, a Bielorrússia? Não é incomum, na atualidade, principalmente no Ocidente, encontrar insinuações e afirmações que o retratam de forma ideologicamente depurada - quando não bastante deturpada -, como se ele estivesse à margem do processo político, histórico e revolucionário por que passavam a Rússia e países vizinhos, inclusive a Bielorrússia, seu país. Chega-se mesmo a afirmar que ele não teria aderido à Revolução. Contudo, atualmente estão sendo publicados textos escritos por ele, naquela época, que evidenciam não apenas sua preocupação com os acontecimentos na Rússia, mas sua conclamação aos judeus, às organizações partidárias e movimentos sociais judaicos para aderir ao processo revolucionário que estava em curso e que levaria à instalação do poder soviético.

Desde que começamos a nos dedicar ao estudo das obras de Vigotski, o seu envolvimento com a Revolução de Outubro parecia-nos quase certo, pois a leitura de seus textos permitia ver, com clareza, que os seus fundamentos são bastante distintos daqueles que inspiraram - e ainda inspiram - grande parte da psicologia ocidental. Além disso, afirma-se, reiteradamente, a base materialista, histórica e dialética de suas proposições teóricas. Ora, então, como seria possível a esse jovem de pouco mais de vinte anos não se envolver com a Revolução de Outubro? A possibilidade estava posta. Entretanto, carecíamos de evidências que demonstrassem o seu envolvimento político direto. Por sua vez, a sua relação com a questão judaica mostrava-se bem mais opaca, pois não se dispunha de informação segura sobre suas ligações com o judaísmo, a não ser que seu pai era judeu.

No início dos anos 2000, realizávamos estudos sobre a ética buberiana sob a orientação do Professor Roberto Bartholo, da Universidade Federal do Rio de Janeiro. Nas leituras e discussões que realizávamos, começamos a verificar muitas convergências entre ideias de Martin Buber e de Vigostki, o que motivou um aprofundamento nos estudos para comparação dos dois estudiosos. Dessa 
busca resultou um texto que publicamos (TUNES; BARTHOLO, 2004), tratando de uma dessas convergências. Nele, partimos de uma síntese do modo como Vigotski formulara o problema do estudo da consciência e fomos em direção ao exame que ele fazia da transformação da experiência de outros em experiência individual e, em consequência, como definia o que seria o homem (para ele, seria a personalidade social $=o$ conjunto de relações sociais, encarnado no indivíduo - (VIGOTSKI, 2000, p. 33 , grifos dele). A partir desse ponto, tomamos o conceito de zona de desenvolvimento iminente (à época, ainda empregávamos a palavra proximal no lugar de iminente) como exemplar para tecer comparações com ideias de Martin Buber e demonstrar que ambos convergiam para a ideia de que o homem é "o ente apto ao relacionamento pessoal com a alteridade”, é o ser-em-relação (TUNES; BARTHOLO, 2004, p. 53). Seguiram-se duas outras publicações em que outras comparações foram feitas entre ideias dos dois estudiosos (TUNES; TACCA; BARTHOLO, 2005; BARTHOLO; TUNES; TACCA, 2010). Sem dúvida alguma, Martin Buber é um pensador de inspiração hassídica (ver BARTHOLO, 2001) e, assim, parecia haver um pequeno indício que justificativa a continuidade de nossa busca por outros indícios e evidências do envolvimento de Vigotski com a questão judaica. Ainda em 2003, tivemos acesso ao prefácio que Guillermo Blanck fez à obra Psicologia Pedagógica, de Vigotski, no qual ele afirma que a vida profissional desse grande homem é narrada como se tivesse sido iniciada em 1924, nada mais se afirmando a não ser que era um simples professor e que se dedicara à literatura e ao teatro: "Nunca se menciona o judaísmo de Vigotski, com todas as implicações que esse teve para explicar decisivos aspectos de sua vida e carreira" (BLANCK, 2003, p. 16). Ainda, Blanck (2003, p. 30) informa que Vigotski teve seu bar mitzva e que, em sua infância, houve dois pogroms em Gomel (em 1903 e 1906) e seu "pai participou da autodefesa judia do primeiro, um dos poucos em que os cossacos não triunfaram”. Eis aí fortes indícios da possibilidade de envolvimento de Vigotski com a questão judaica.

Seguindo, então, nossa busca, em viagem que fizemos à Moscou, em 2007, tivemos oportunidade de entrevistar Guita Lvovna Vigodskaia, sua filha mais velha. Naquela ocasião, perguntamos-lhe se ele era uma pessoa religiosa e ela respondeu que não poderia responder com precisão. Então, em seguida, indagamos se a família festejava as datas judaicas. Ela nos disse que:

Não, só a Páscoa. Nada mais. Até, quando menina eu disse a minha avó: 'Você não segue as tradições!'. Ela me disse:

'A Páscoa é uma tradição que é para mim muito querida porque me traz lembranças da infância e da juventude'. Então, quando era Páscoa, tirava-se a louça pascoal, lavava-se e durante uma semana ela e meu avô faziam matsuri. Era a única tradição, e o vovô antes da Páscoa ia à Sinagoga. Depois, vinha a Páscoa ortodoxa e a festejavam por causa da babá (PRESTES, 2010).
Nessa mesma entrevista, Guita informou-nos que seu pai havia sido eleito para deputado por dois mandatos, embora não tenha concluído o segundo devido à sua morte. Frisou, contudo, que ele não pertencera ao partido (comunista). Evidentemente, para nós, esta última informação não significava que sua atuação não tenha sido política. Afinal, ser deputado significa ser um homem público o que, necessariamente, acarreta o exercício de ações políticas, sejam elas quais forem.

Embora a entrevista com Guita Lvovna Vigodskaia não tenha sido conclusiva e oferecido pistas férteis para nossas buscas, seguimos em frente, sempre com a mente atenta. A nossa busca fortalecia-se à medida que conversávamos com pesquisadores russos que, de algum modo, haviam tido acesso a textos e fragmentos de textos de Vigotski guardados no arquivo de sua família.

Foi, então, que, em nossa caminhada, com muita sorte no bolso, tivemos a oportunidade de, em 2015, conhecer o Professor Vladimir Samuilovitch Sobkin, da Academia Russa de Educação. Prontamente o convidamos para participar do VERESK III, realizado em junho de 2016 na cidade de Niterói, na Faculdade de Educação da Universidade Federal Fluminense (FEUFF). Sua palestra foi publicada, em português e russo, no terceiro volume dos Cadernos Acadêmicos Internacionais - VERESK (SOBKIN, 2017). Ele também foi o redator, comentarista e organizador das resenhas teatrais que se encontram no primeiro volume das obras completas de Vigotski (2015), tendo publicado um livro a esse respeito (SOBKIN, 2015).

Em 2016, o professor Vladimir Samuilovitch Sobkin publicou um artigo na revista Natsionalni Psirrologuitcheski Jurnal (Национальный психологический журнал - [SOBKIN, 2016]) em que são reproduzidos e comentados três artigos de Vigotski, de um total de nove, que saíram na revista judaica semanal Novi Put' e eram praticamente desconhecidos até hoje. Assinados com as iniciais $L$. S. ou $W$, o primeiro artigo reproduzido e analisado por Sobkin saiu em meados de julho e os outros dois, no início de setembro de 1917. Esses artigos revelam as impressões e a opinião de Vigotski a respeito do comportamento de comunidades de judeus - que tinham autorização para residir apenas em territórios delimitados (Rayon) pelo regime monárquico russo - em relação ao movimento revolucionário que estava em curso na Rússia. Além de serem documentos históricos, os artigos de Vigotski apresentam informações valiosas sobre a participação de grupos políticos e partidos judaicos no movimento revolucionário de 1917, trazendo à luz aspectos que podem ajudar a compreender o posicionamento político de Vigotski e sua identificação com as transformações advindas com a Revolução de Outubro. Eis os textos:

Primeiro texto, publicado em 15 de julho de 1917 e assinado por L. S.:

- "Eleições para a Duma (Parlamento) da cidade"

Segundo texto, publicado em 3 de setembro de 1917 e assinado por L. S.:

- "Notas da província" 
Terceiro texto, publicado em 3 de setembro de 1917 e assinado por W.: 1

- "Gomel. Conferência s/d"

A tônica comum aos três textos é uma visão crítica em relação à comunidade judaica da província em função dos acontecimentos na Rússia revolucionária. Além disso, há uma análise do processo eleitoral. Vigotski chama a atenção para a política partidária tensa, fazendo também menção à União Geral Judaica dos Trabalhadores (Bund) - uma organização importante de judeus que teve participação ativa no processo revolucionário. Ainda, ele demonstra uma grande sensibilidade para perceber e analisar os acontecimentos que estavam em curso.

Na verdade, os textos de Vigotski são evidências escritas de próprio punho que demonstram, sem sombra de dúvida, que:

Ele não estava alheio ao processo político revolucionário da Rússia;

Acompanhava atentamente o desenvolvimento dos acontecimentos políticos e percebia os reflexos deles em seu país, Bielorrússia;

Atentava para a total ineficiência das ações políticas na comunidade judaica, em função da indiferença que demonstravam em relação às grandes questões judaicas;

Destacava a importância de os movimentos e partidos judaicos participarem das eleições parlamentares;

Alertava para o perigo do olhar dirigido apenas para os "horizontes de pogroms".

Além de informações importantes sobre suas impressões a respeito do processo revolucionário, os textos de Vigotski mostram também sua preocupação com os movimentos sociais judaicos e partidos políticos judeus, bem como trazem à tona análises interessantes a respeito de como ele enxergava a participação dos judeus na Revolução de Outubro. Os dados e comentários complementares magistralmente apresentados por Sobkin são o resultado de verdadeiras escavações arqueológicas sobre personagens ocultos nos textos que desempenharam um papel importante em prol dos movimentos judaicos de então. Um exemplo é a atuação do pai - Semion Lvovitch - em uma organização beneficente a que se refere Vigotski no terceiro texto.

Entendemos que as evidências com que Sobkin nos presentou devem ser compartilhadas com leitores da língua portuguesa. Por isso, seu artigo foi traduzido para o português e é apresentado seguindo este nosso texto.

\section{REFERÊNCIAS}

BARTHOLO, R. Você e eu. Martin Buber - presença palavra. Rio de Janeiro: Garamond, 2001.

BARTHOLO, R.; TUNES, E.; TACCA, M. C. V. R. Vygotsky's and Buber's Pedagogical Perspectives: Some Affinities. Educational Philosophy and Theory (Print), v. 42, p. 867-880, 2010.

BLANCK, G. (Org.). Prefácio. In: . Psicologia pedagógica: Liev Semionovich Vigotski. Tradução de Claudia Schilling. Porto Alegre: Artmed, 2003. p. 15-32. Edição comentada.

DAVIDOV, V. V. Psirrologuitcheskaia nauka v SSSR. Jurnal Voprosi Prirrologuii, Moskva, n. 6, p. 21-31, 1982.

PRESTES, Z. Guita Ivovna (sic) Vigodskaia (1925-2010), filha de Vigotski: entrevista. Cadernos de Pesquisa (Fundação Carlos Chagas), São Paulo, v. 40, n. 41, p. 1025-1033, 2010. Cross ${ }^{\text {Ref. }}$

PRESTES, Z. Quando não é quase a mesma coisa: traduções de Lev Semionovitch no Brasil. Campinas, SP: Autores Associados, 2012.

SOBKIN, V. S. Vstupitelnaia statia. L. S. Vigotski i teatr: abris sotsioculturnogo konteksta. In: VIGOSTKI, L. S. Polnoie sobranie sotchineni. Moskva: Lev', 2015. v. 16, t. 1, p. 10-75.

SOBKIN, V. S.; KLIMOVA, T. A. Lev Vigotski mejdu dvurh revoliutsii: $\mathrm{k}$ voprossu o polititcheskom samoopredelenii utchionogo. Natsionalni psirrologuitcheski jurnal, Moskva, v. 3, n. 23, p. 20-31, 2016.

SOBKIN, V. S. As resenhas teatrais de L. S. Vigotski como início da concepção histórico-cultural. VERESK - Cadernos Acadêmicos Internacionais: estudos sobre a perspectiva histórico-cultural de Vigotski, Brasília, UniCEUB, p. 7-33, 2017.

TUNES, E.; TACCA, M. C. V. R.; BARTHOLO, R. O professor e o ato de ensinar. Cadernos de Pesquisa (Fundação Carlos Chagas), São Paulo, v. 35, n. 126, p. 689-698, 2005.

TUNES, E.; BARTHOLO, R. Da constituição da consciência a uma psicologia ética: alteridade e zona de desenvolvimento proximal. In: SIMÃO, L. M.; MARTINEZ, A. M. (Org.). $O$ outro no desenvolvimento humano. São Paulo: Pioneira Thomson Learning, 2004. p. 41-60.

VIGOSTKI, L. S. Psicologia concreta do homem. Educação \& Sociedade, Campinas, v. 21, n. 71, p. 21-44, 2000.

VIGOSTKI, L. S. Polnoie sobranie sotchineni. Moskva: Lev', 2015. v. 16 , t. 1.

Recebido em: 28 de novembro de 2017

Aceito em: 7 de dezembro de 2017

${ }^{1} \mathrm{~A}$ respeito dessa assinatura (W), é interessante consultar Prestes (2012). 